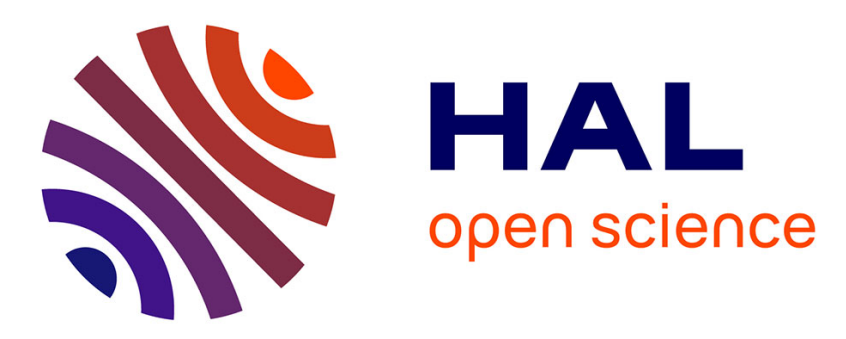

\title{
Anaphora resolution in near-native speakers of Italian
}

Antonella Sorace, Francesca Filiaci

\section{To cite this version:}

Antonella Sorace, Francesca Filiaci. Anaphora resolution in near-native speakers of Italian. Second Language Research, 2006, 22 (3), pp.339-368. 10.1191/0267658306sr271oa . hal-00572103

\section{HAL Id: hal-00572103 https://hal.science/hal-00572103}

Submitted on 1 Mar 2011

HAL is a multi-disciplinary open access archive for the deposit and dissemination of scientific research documents, whether they are published or not. The documents may come from teaching and research institutions in France or abroad, or from public or private research centers.
L'archive ouverte pluridisciplinaire HAL, est destinée au dépôt et à la diffusion de documents scientifiques de niveau recherche, publiés ou non, émanant des établissements d'enseignement et de recherche français ou étrangers, des laboratoires publics ou privés. 


\title{
Anaphora resolution in near-native speakers of Italian
}

\author{
Antonella Sorace and Francesca Filiaci University of \\ Edinburgh
}

Received December 2005; revised March 2006; accepted March 2006

This study presents data from an experiment on the interpretation of intrasentential anaphora in Italian by native Italian speakers and by English speakers who have learned Italian as adults and have reached a near-native level of proficiency in this language. The two groups of speakers were presented with complex sentences consisting of a main clause and a subordinate clause, in which the subordinate clause had either an overt pronoun or a null subject pronoun. In half of the sentences the main clause preceded the subordinate clause (forward anaphora) and in the other half the subordinate clause preceded the main clause (backward anaphora). Participants performed in a picture verification task in which they had to indicate the picture(s) that corresponded to the meaning of the subordinate clause, thus identifying the possible antecedents of the null or overt subject pronouns. The patterns of responses of the two groups were very similar with respect to the null subject pronouns in both the forward and backward anaphora conditions. Compared to native monolingual speakers, however, the near-natives had a significantly higher preference for the subject of the matrix clause as a possible antecedent of overt subject pronouns, particularly in the backward anaphora condition. The results indicate that nearnative speakers have acquired the syntactic constraints on pronominal subjects in Italian, but may have residual indeterminacy in the interface processing strategies they employ in interpreting pronominal forms. 


\section{Introduction}

One of the generalizations that has emerged from studies of the endstate grammar of very advanced and near-native speakers is that grammatical aspects that involve an interface between syntax and other cognitive systems often present residual first language (L1) effects, indeterminacy or optionality (Sorace, 2000; 2003; 2005). In contrast, there is currently no evidence of optionality in near-native grammars with respect to syntactic properties in a narrow sense. ${ }^{1}$ This generalization has led to the hypothesis that narrow syntactic properties are completely acquirable in a second language, even though they may exhibit significant developmental delays, whereas interface properties involving syntax and another cognitive domain may not be fully acquirable. Let us refer to this as the Interface Hypothesis. This hypothesis has been found to have wider applicability in other domains of language development, such as bilingual L1 acquisition, L1 attrition, language breakdown and diachronic change. Second language acquisition is therefore aligned with other developmental domains in current research on interface phenomena, as Section II below illustrates.

The empirical exploration of the interface hypothesis raises the question of the reasons that may underlie the developmental optionality found at interfaces, although there is of course no reason to expect that the same causes may be at the root of optionality in different developmental domains. Two broad types of explanations have been proposed: one is that optionality is the result of un(der)specification at the level of knowledge representations; the other is that it stems from insufficient processing resources to integrate the multiple types of information involved at the interfaces between syntax and other cognitive domains. The latter explanation appears to receive support from recent research on L2 processing. This research has in fact highlighted the possibility

\footnotetext{
${ }^{1}$ Some theories of L2 acquisition posit a 'representational deficit' in L2 acquisition, i.e. a permanent inability in L2 learners to represent new functional features globally (Hawkins and Chan, 1997; Hawkins, 2001) or a more restricted inability to represent uninterpretable features not instantiated in the L1 (Tsimpli, 1997). However, these theories are based on developmental data from intermediate or advanced L2 speakers, but not on data from near-native speakers. They are therefore consistent with the assumption that some narrow syntax features pose developmental problems, but they have not demonstrated that such features are unacquirable.
} 
that much of the divergence exhibited by non-native grammars may result not so much from representational deficits, but from inadequate processing resources or 'shallow' parsing strategies (Clahsen and Felser, 2006; see also Hopp, this issue). It is in this key that some of the results from previous research on interfaces may be re-interpreted (for suggestions, see Sorace, 2006).

The study presented here is meant to contribute to the ongoing debate on the sources of residual and potentially permanent optionality in near-native grammars. The focus is on the syntax of pronominal subjects as a particularly fruitful ground to test the Interface Hypothesis. In null subject languages, null subjects are syntactically licensed but their distribution is pragmatically determined (Grimshaw and SamekLodovici, 1998; Holmberg, 2005, among others). Mastery of pronominal subjects in null subject languages therefore requires both the correct representation of the syntactic licensor(s) (i.e. the correct setting of the null subject parameter, in traditional principles-and-parameters models of generative grammar) and knowledge of the pragmatic interface conditions that govern the felicitous use of null or overt subject pronouns in context. While there is some consensus on the composite nature of the knowledge underlying the appropriate use of subject pronouns in null subject languages, the specific processing constraints involved in the comprehension and production of subjects have not until recently been the focus of systematic inquiry in research on language development. In this study, a particular proposal on the nature of these constraints in Italian is considered and its relevance is explored for the interpretation of experimental comprehension data from near-native Italian speakers. It will be shown that the Interface Hypothesis may apply to the domain of processing, without excluding the possibility of crosslinguistic effects on representations.

The article is organized as follows. Section II reviews the developmental research that has explored the Interface Hypothesis in different populations of bilingual speakers. Section III outlines some theories of language processing that have been proposed recently for the interpretation of subject pronouns and for anaphora resolution. Section IV describes the details of the experimental study and Section $V$ reports the results. Finally, Sections VI and VII present a discussion of the results and the conclusions. 


\section{Interface conditions on pronominal subjects: the wider developmental picture}

\section{$1 \quad$ L1 attrition}

The syntax-discourse conditions on the distribution of pronominal subjects have been shown to be developmentally vulnerable to optionality in the native language of speakers in a situation of prolonged exposure to a second language. The visible manifestation of $\mathrm{L} 1$ attrition in the native null subject language of highly proficient L2 speakers of English is the pragmatically inappropriate extension of the overt subject pronoun to contexts that require the use of a null subject among monolinguals. This extension is attested in native speakers of various null-subject languages, such as Catalan (Helland, 2004), Italian and Greek (Cardinaletti, 2005; Tsimpli et al., 2004) and Spanish (Montrul, 2004). Null subjects, in contrast, normally appear to be target-like in all contexts in which they are used. A typical example from spontaneous production is shown in (1):

1) Paola ${ }_{i}$ non ha telefonato perché lei $i_{i}$ è uscita presto.

'Paola ${ }_{i}$ has not telephoned because she $_{i}$ has left early'.

Moreover, Tsimpli et al. (2004) found evidence of misinterpretation of overt - but not null - pronouns in ambiguous forward and backward anaphora sentences, in which the main clause contained two samegender referents that could both be plausible antecedents, as in $(2 \mathrm{a}-\mathrm{b})$ :

2) a. Il portiere ${ }_{i}$ saluta il postino ${ }_{l}$ mentre $\phi_{i} /$ lui $_{i / l}$ apre la porta.

'The porter ${ }_{i}$ greets the $\operatorname{postman}_{l}$ while $\emptyset_{i} /$ he $_{i / l}$ opens the door'.

b. Mentre $\phi_{i} /$ lei ${ }_{i / l}$ parla la maestra $_{i}$ indica l'alunna $_{l}$. 'While $\emptyset_{i} /$ she $_{i / l}$ talks the teacher ${ }_{i}$ points at the pupil' '.

Italian speakers under attrition from English are significantly more likely than native monolingual speakers to interpret the overt pronoun lui as coreferential with the matrix subject il portiere in the forward anaphora context in (2a); similarly, they are more likely to interpret the pronoun lei in the backward anaphora sentence in (2b) as referring to the subject la maestra. Tsimpli et al. note that there are differences in the overall patterns of interpretation for forward anaphora and backward anaphora in both the experimental and the control groups, but they do not discuss the possible underlying reasons for these discrepancies.

These asymmetric attrition effects on subject pronouns are explained by Tsimpli et al. as being due to the emerging influence of the L2 
(English) on interpretable features in the L1 representations. These features, such as the feature [ + topic shift] that Italian maps onto overt pronouns, are 'eroded' by the constant use of a language like English, in which there is no choice of pronominal forms regulated by interface conditions. The result is underspecification at the syntax-discourse interface and, therefore, ambiguity in production and interpretation of overt subject pronouns. The syntactic features responsible for the licensing of null subjects, however, is unaffected by attrition.

Studies of generational attrition due to language contact confirm that the effects of the change in the pronominal system initiated in firstgeneration speakers at the individual level are more pronounced and widespread in second-generation speakers. Lapidus and Otheguy (2005), Montrul (2004) and Toribio (2004) all illustrate the phenomenon of 'convergence' in Heritage Spanish speakers as over-extension of overt subject pronouns to contexts that would call for the use of null pronouns. Lapidus and Otheguy, however, argue that language contact magnifies a situation already existing before the onset of attrition: some variability in the use of overt pronouns is in fact found in pre-contact varieties of Spanish. It will be seen in Section 3 that this type of variability may be a more general characteristic of pronominal subject use in native speakers of null subject languages.

\section{Bilingual first language acquisition}

Longitudinal studies of young bilingual children acquiring two languages simultaneously from birth confirm that the interface conditions on the use of subject pronouns are susceptible to developmental delays and crosslinguistic influence. Most of these studies are based on spontaneous production data; they focus on children who acquire a null subject language and a non-null subject language and live in the country where the non-null subject language is spoken. The consistent pattern that has emerged from these studies (e.g. Hacohen and Schaeffer, 2005 for Hebrew-English bilinguals; Müller et al., 2002; 2006 for Italian-German bilinguals; Paradis and Navarro, 2003 for Spanish-English bilinguals; Pinto, 2004 for Italian-Dutch bilinguals; Serratrice et al., 2004 for Italian-English bilinguals) is that there is an influence of the non-null subject language on the null subject language, 
manifested in the overuse of overt pronouns in the null subject language. No overuse of null subjects is reported in the non-null subject language, even at the earliest stages when the null subject language may be expected to reinforce the well-attested tendency of children acquiring a non-null subject language to go through a stage of subject omission (for a summary, see Guasti, 2002). This asymmetric pattern has been interpreted by various researchers within Müller and Hulk's (2001) proposal on crosslinguistic influence in bilingual first language acquisition. Their proposal in fact assumes that the likelihood of crosslinguistic influence is enhanced when (1) the two languages overlap with respect to a given grammatical property, and (2) this property involves the interface between syntax and pragmatics. However, it is not clear why crosslinguistic influence in the syntax of pronominal subjects should consistently lead to over-production of overt pronouns in the null subject language. In fact Müller and Hulk's proposal does not make clear predictions about directionality of influence in this specific domain and, indeed, it may be plausible to expect crosslinguistic influence to go in the opposite direction, at least in the early stages of bilingual development. ${ }^{2}$

\section{Pronominal subjects in L2 acquisition}

Research on the L2 syntax of subjects outlines a parallel picture with respect to L1 attrition and bilingual L1 acquisition. Belletti et al. (2005) and Filiaci (2003) show that near-native speakers of Italian, tested both in Italy and Scotland, are significantly more likely than native speakers to use redundant overt pronouns in both spontaneous and elicited production tasks, and to misinterpret anaphoric overt pronouns as referring to the subject of the main clause. In contrast, no differences are observed with respect to the use and interpretation of null pronouns. The off-line data in these studies are consistent with an account that places the problem at the level of underspecified interpretable features

\footnotetext{
${ }^{2}$ For discussion see Serratrice et al., 2004 Müller and Hulk's proposal is based on data from young bilingual children who have not yet acquired the syntax of the C-domain. At this stage, children have been found to rely on pragmatic licensing of null arguments; see Roeper's (1999) concept of Minimal Default Grammar. Crosslinguistic influence may reinforce an option already present in this early grammar, such as subject omission. No prediction is made for stages subsequent to Minimal Default Grammer, when syntactic knowledge is target-like.
} 
in L2 representations due to the availability and residual influence of native English. This is the same explanation that was developed for L1 attrition, but in the opposite direction: the most 'economical' system that does not involve syntax-discourse interface conditions on subject realization (i.e. English) affects the one that does (Italian), regardless of whether English is the native or the non-native language.

An indication that transfer from English may not be the only explanation, however, comes from earlier spontaneous production data from lowintermediate Spanish learners of Italian (Bini, 1993), who use redundant subject pronouns in Italian in contexts in which both Spanish and Italian would require a null pronoun. An example from Bini's study is in (3).

3) Mia sorella e mio cognato escono per il lavoro e loro lavorano a Paseo de la Castellana.

'My sister and my brother-in-law go out to work and they work at Paseo de la Castellana'.

Since L1 influence cannot be a factor in this case, it is conceivable that overt pronouns may be a default form employed to compensate for poorlyautomatized morphological knowledge (Sorace, 2005). ${ }^{3}$ This conjecture raises the possibility that the use of overt pronouns may be a more general default strategy at all proficiency levels (although the problems faced by L2 speakers may of course be different), and independent of the typological similarity between L1 and L2. Indeed, even native speakers may be expected to resort to this default in a situation of processing overload.

In line with these considerations, Sorace $(2004 ; 2005)$ speculates that developmental instability at interfaces may be - at least in part - the result of inefficient processing strategies to coordinate syntactic and pragmatic knowledge. This may be a factor that favours residual optionality in early and late bilingualism, and emerging optionality in L1 attrition. Moreover, it may be a factor that acts in conjunction with, rather than instead of, crosslinguistic influence: when one of the bilingual

\footnotetext{
${ }^{3}$ The possibility of L1 transfer could not be excluded, however, if it could be shown that Italian and Spanish are different types of null subject languages. While an in-depth discussion of this topic would be outside the scope of this article, it is important to mention that differences (with respect to the status of subjects in Spanish, for example) have in fact been pointed out in the syntax literature (e.g. Ordóñez and Treviño, 1999). See also Carminati (2002) on the suggestion (briefly mentioned in Section VI) that there may be microvariation among null subject languages in the antecedent assignment possibilities for overt subjects.
} 
speaker's languages is a non-null subject language, the combination of sub-optimal processing resources and crosslinguistic influence may increase the magnitude of the effects. The first step in testing this alternative hypothesis on the nature of interface instability is to examine the processing strategies normally employed by native speakers in anaphora resolution.

\section{Processing of anaphoric subject pronouns in null-subject languages}

Recently, Carminati $(2002$; 2005) proposed a theory of pronoun antecedent assignment in Italian based on the assumption that null and overt pronouns have distinct and complementary functions, manifested in their distinct biases for antecedents in different syntactic positions. Null pronouns have a strong bias towards an antecedent in Spec IP, whereas overt pronouns prefer an antecedent in positions lower in the phrase structure: this is referred to as the Position of Antecedent Strategy (PAS). The constituent in Spec IP is normally, but not exclusively, the preverbal subject of the sentence and tends to be interpreted as the topic. The PAS, however, does not distinguish between canonical and non-canonical subjects (see the dative subject in 4), or between referential and non-referential subjects (as the quantified DP in $5 \mathrm{a}$ and the bare quantifier in $5 \mathrm{~b}$ ). 4,5

4) Dato che a Mario $_{i}$ non piace Gianni, $\phi_{i}$ cerca di evitarlo. since to Mario $_{i}$ not like Gianni, $\phi_{i}$ tries to avoid-CL 'Since Mario doesn't like Gianni he tries to avoid him'.

5) a. Al colloquio per il posto di lavoro, ogni candidata ${ }_{i}$ ha detto che $\emptyset_{i} /$ lei $_{k}$ vorrebbe prendere le ferie in Agosto.

'At the interview for the post, every candidate ${ }_{i}$ has said that $\emptyset_{i} /$ she $_{k}$ would like to take holidays in August'.

b. Al colloquio per il posto di lavoro, ognuno ${ }_{i}$ ha detto che $\phi_{i} /$ lui $_{k}$ vorrebbe prendere le ferie in Agosto.

'At the interview for the post, everyone ${ }_{i}$ said that $\emptyset_{i} / \mathrm{he}_{k}$ would like to take holidays in August'.

\footnotetext{
${ }^{4}$ Montalbetti's (1984) Overt Pronoun Constraint would predict that it should be impossible for an overt pronoun in subject position to receive a bound variable reading; so (5a) and (5b) should be equally ungrammatical with an overt pronoun coreferential with the subject. Carminati instead found that, although the null pronoun is always preferred in this reading, sentences with overt pronouns and quantified DPs, in which gender features of the DP matched those of the pronoun, were read faster than sentences with bare quantifiers.

${ }^{5}$ The following and many other examples in this section are taken from Carminati (2002).
} 
Thus, the initial antecedent assignment in anaphora resolution is structurally based. If the predicate is pragmatically construed to contradict the PAS, reanalysis is necessary and this incurs a measurable processing cost: for example, the sentence in (6b) elicits longer reading times than the sentence in (6a). Similarly, phi-features (gender, person and number) may work in tandem or against the PAS: incongruences between the PAS and these features - as in (7a) with an overt pronoun and (7b) with a null pronoun - are costly in processing terms. ${ }^{6}$ As has been claimed by many studies over the last 15 years, extra-syntactic mechanisms require more processing resources than syntactic mechanisms; the processor always tries to establish a syntactic dependency whenever possible (for a review, see Burkhardt, 2005).

6) a. Quando Vanessa ${ }_{i}$ ha visitato Giovanna in ospedale, $\varnothing_{i}$ le ha portato un mazzo di fiori.

when Vanessa ${ }_{i}$ has visited Giovanna at the hospital, $\emptyset_{i}$ to her has brought a bunch of flowers.

'When Vanessa ${ }_{i}$ visited Giovanna at the hospital, she ${ }_{i}$ brought her a bunch of flowers.'

b. ? Quando Vanessa ha visitato Giovanna ${ }_{k}$ in ospedale, $\varnothing_{k}$ era già fuori pericolo. 'When Vanessa visited Giovanna ${ }_{k}$ in the hospital, she $_{k}$ was already out of danger'.

7) a. Quando Mario $_{i}$ chiama Giovanna ${ }_{k}, \emptyset_{i} /$ ?lui ${ }_{i}$ è contento. When Mario $_{i}$ calls Giovanna ${ }_{k}, \emptyset_{i} /$ ?he ${ }_{i}$ is happy-M

b. Quando Mario ${ }_{i}$ chiama Giovanna ${ }_{k}, ? \emptyset_{k} /$ lei $_{k}$ è contenta. When Mario $_{i}$ calls Giovanna ${ }_{k}, ? \varnothing_{k} /$ she $_{k}$ is happy-F

These biases have been shown to have a generalized application covering both referential and non-referential antecedents in Spec IP, one- and two-referent contexts, and both ambiguous and unambiguous contexts. The PAS therefore seems to be a highly efficient processing principle for resolving pronoun-antecedent dependencies in null-subject languages like Italian. However, the PAS is unlikely to belong to the syntax proper, since its violations do not, in most cases, give rise to ungrammaticality, but rather to inappropriateness (although violations of the PAS in ambiguous contexts may lead to misunderstanding: see below). The place of the PAS, therefore, is the interface between syntax and

${ }^{6}$ Carminati (2002: 39) assumes that adverbial clauses are either base-generated in an IP-initial position or in a Top(ical) position in CP. In the forward and backward anaphora sentences investigated here, coreference between the pronouns and their potential antecedents is always structurally possible (i.e. it does not violate Principle B) because the pronoun does not have a c-commanding antecedent in the same clause. 
discourse pragmatics. As Carminati herself suggests, not only is there a reliable correspondence between the structural position Spec IP and the notion of topic, but pragmatic principles are also the core of antecedent preferences. So, for example, using an overt pronoun to refer to an accessible topic antecedent would represent a violation of Grice's maxim of quantity, because a less complex form - the null pronoun - is available for the same purpose, and should have been used instead.

However, there is a difference between null and overt pronouns with respect to the strength of the PAS: while the preference of null pronouns for antecedents in Spec IP is very robust and almost exceptionless, the overt pronoun shows more flexibility in its antecedent preferences: thus, the experimental evidence in Carminati's work shows that a weaker processing cost may be incurred if an overt pronoun takes a subject antecedent than if a null pronoun takes a non-subject antecedent. The antecedent preferences of overt pronouns appear to be sensitive to contextual factors: the grammar is more tolerant of PAS violations in unambiguous sentences, in which the potential for miscommunication is low. Speakers seem to apply an 'Avoid Miscommunication' principle that involves stricter observance of the PAS for overt pronouns when its use to refer to the subject antecedent would lead to misinterpretation (as in (8a), in which both NPs are plausible antecedents for the pronoun), and relaxation of the PAS when this use of overt pronouns does not mislead the language processor (as in (8b), where there is only one referent, or (8c), where number unambiguously identifies the antecedent). ${ }^{7}$

8) a. Maria ${ }_{i}$ scriveva spesso a Piera ${ }_{k}$ quando lei ${ }_{\text {?? } i k}$ era negli Stati Uniti. 'Maria ${ }_{i}$ used to write often to Piera $_{k}$ when she $_{\text {??i/k}}$ was in the USA'.

b. Gregorio ${ }_{i}$ ha detto che lui ${ }_{i}$ sarà presente al matrimonio di Maria.

'Gregorio ${ }_{i}$ has said that he will be present at the wedding of Maria'.

c. Quando Gianni ${ }_{i}$ ha salutato i nonni, lui ${ }_{i}$ era veramente triste.

'When Gianni ${ }_{i}$ said goodbye to his grandparents he ${ }_{i}$ was very sad'.

The attested flexibility of antecedent assignment with overt pronouns in native monolingual speakers raises the interesting question of whether

\footnotetext{
${ }^{7}$ The interesting prediction made possible by this processing account is that null subject languages may vary with respect to the distance (in terms of clear division of labour) between the null and the overt pronoun. Given the strength of the antecedent bias of null pronouns (for a discussion of how the PAS works in Spanish, see Alonso-Ovalle et al., 2002), crosslinguistic variation may in fact lie in the degree of tolerance of different null subject languages for the use of the overt pronoun in contexts that would require the use of a null pronoun. This is in fact what the survey in Carminati (2002: 197) shows.
} 
the over-production of overt subjects that has been attested in bilingual speakers is in line with the 'Avoid Miscommunication' principle. If the redundancy in the null subject grammar of bilingual speakers is of the same type as in monolingual speakers, one would expect bilingual speakers not to produce or misinterpret overt pronouns as coreferential with a subject antecedent when the sentence is globally ambiguous, as in the intrasentential anaphora contexts that are the object of this study.

\section{Processing differences between forward and backward anaphora}

Most of Carminati's experiments involved bi-clausal sentences in which the main clause contained the null or overt pronoun. However, the bilingual studies reviewed above, as well as the experiment reported in this study, focus on anaphora resolution in bi-clausal sentences in which the pronoun is in the subordinate clause. In forward anaphora, in which the main clause precedes the subordinate clause, the processor encounters both referents before the pronoun. In backward anaphora, which has the subordinate-main order of clauses, the pronoun is encountered prior to the mention of any referents. This type of anaphora resolution poses particular demands to the processor because the pronoun linearly precedes the potential referents and so there are no discourse constraints on antecedent assignment. Research on processing of backward anaphora in English has shown the parser actively tries to complete the pronoun-antecedent dependency as soon as possible, even in the absence of bottom-up information. More specifically, the parser:

- immediately starts the search for an antecedent and restricts the search space to antecedents that are syntactically legitimate (i.e. that do not violate Principle C; see Cowart and Cairns, 1987; Kazanina, 2005);

- evaluates each subsequent NP as potential antecedents in succession as they are encountered (Kazanina et al., 2005); and

- has an expectation to solve the anaphoric dependency in the matrix subject position (van Gompel and Liversedge, 2003).

Bi-clausal backward anaphora sentences with overt pronouns, in which both referents in the main clause occupy positions that are syntactically licit for antecedent assignment, should be particularly costly in processing terms because they present a conflict to the processor. On the one 
hand, the parser is structurally biased to complete the dependency in the matrix subject position; on the other hand, the PAS biases the processor to avoid subject antecedent assignment for an overt pronoun. It will be seen in Section 5 that native and near-native speakers adopt different solutions to this conflict.

In light of what is known about the processing of pronominal subjects, one can redefine the task of the L2 learner of a null-subject language as one that involves acquiring:

- the syntactic conditions on the licensing of null subjects;

- the discourse conditions on the contextual distribution of pronominal forms; and

- the processing strategies for the correct on-line production and interpretation of subject pronouns.

If differences are found between native and near-native speakers, which of these components might be responsible for them? This study explicitly addresses this question.

\section{The study}

The present study was part of a wider project on the syntax of pronominal subjects in near-native speakers of Italian. The data reported here were obtained in an off-line interpretation task requiring the resolution of ambiguous anaphoric dependencies between null and overt pronouns and inter-sentential antecedents. The hypotheses were that:

- Native and near-native speakers would differ in their interpretation of overt pronouns, but not in their interpretation of null pronouns.

- Near-native speakers would allow overt pronouns in subordinate clauses to co-refer with the subject of the matrix clause.

- Forward and backward anaphora would pose different processing demands, and near-natives would differ more from natives with respect to backward anaphora than forward anaphora.

\section{Method}

a Participants: Two groups of speakers participated in the study: a control group of monolingual Italian natives speakers (NS) and a group 
of native English speakers who had attained near-native proficiency in Italian (NNS). The control group consisted of 20 monolingual Italian speakers between the ages of 22 and 57, all resident in Italy, who had never been consistently exposed to English, although some studied English as a foreign language at school. The L2 learner-group consisted of 14 native speakers of English, between the ages of 24 and 64, of American and British origin, who started learning Italian as an L2 after puberty. Their level of proficiency in Italian was assessed using an adapted version of a screening procedure designed by White and Genesee (1996). ${ }^{8}$ All of the participants included in this group were either resident in Italy or had lived in Italy in the past for a period of at least one-and-a-half years.

$b$ Materials: The data were collected using a Picture Verification Task (PVT), as part of an experiment that included a total of four different tasks involving both production and comprehension of null vs. overt pronominal subjects and preverbal vs. postverbal NP subjects. ${ }^{9}$

The PVT was designed to test the interpretation of null and overt subjects in the context of forward and backward anaphora. The experimental items were complex sentences consisting of a main clause and a subordinate clause. The main clause always included an animate subject NP, a transitive verb and an animate object NP; the subordinate clause included either a null or an overt pronominal subject, a verb and an object NP. The subject and object of the main clause were always matched for gender and number, so that the subject pronoun in the subordinate clause could (ambiguously) refer to either of the two. The subordinate clause could either precede the main clause (backward anaphora), as in (9), or follow it (forward anaphora) as in (10).

\footnotetext{
${ }^{8}$ We used a similar screening procedure to that designed by White and Genesee (1996), based on the same criteria (the learner's lexicon, morphology, syntax, phonology and fluency were evaluated independently by two Italian native speakers listening to selected speech samples). However, we set a slightly lower cut-off point to define our speakers as 'near-native'. This is motivated by the fact that, unlike White and Genesee, we did not collect the data in a bilingual country and it is therefore more difficult to find speakers that satisfy the strictest criteria for L2 near-nativeness.

${ }^{9}$ The materials used in this study are an adaptation of those designed and created by Sorace and colleagues (Tsimpli et al., 2004) for a study on first language attrition in Italian and Greek. In order to make the experiment more manageable for $\mathrm{L} 2$ learners, the number of items in each task was slightly reduced, and one of the original tasks, which was time-consuming, was eliminated. For more details about the adaptation of the materials, see Filiaci (2003).
} 
9) Mentre lei ${ }_{k / l} /$ pro $_{i}$ si mette il cappotto, la mamma ${ }_{i}$ dà un bacio alla figlia ${ }_{k}$. while she wears the coat, the mother gives a kiss to the daughter 'While she/pro is wearing her coat, the mother kisses her daughter.'

10) La mamma ${ }_{i}$ dà un bacio alla figlia ${ }_{k}$ mentre $\operatorname{lei}_{k l l} /$ pro $_{i}$ si mette il cappotto. the mother gives a kiss to the daughter, while she wears the coat 'The mother kisses her daughter, while she/pro is wearing her coat.'

There were 20 experimental items of this type, half of them with forward anaphora and the other half with backward anaphora; for each type of anaphora half of the items contained an overt pronominal subject in the subordinate clause and the other half a null subject. Each experimental sentence was presented together with three pictures appearing on the screen below the sentence (for an example, see Appendix 1). In one picture a character ' $A$ ' performed both the action described in the main clause and that described in the subordinate clause; in another picture character ' $\mathrm{A}$ ' performed the action described in the main clause and a character ' $\mathrm{B}$ ' (the direct object in the main clause) performed the action described in the subordinate clause; in the last picture character 'A' performed the action described in the main clause, whereas a third character ' $\mathrm{C}$ ', not mentioned in the main clause but matched in gender with the other two, performed the action described in the subordinate clause.

The task also included fifteen filler items that were only meant to work as distracters.

c Procedure: The experiment was implemented with PsyScope 1.2.5 and run on an iBook with a 12" screen. The order of presentation of the experimental items was randomized for each participant. The relevant instructions were given in English to the near-native group and in Italian to the native group and appeared as text on the screen at the beginning of the task. The participants were instructed to indicate which of the pictures associated with each sentence represented its meaning. Each picture was identified with a number (1,2 or 3) appearing on the screen below it, and the participants were prompted to type in their response after reading the sentence. They were encouraged to indicate all the pictures that corresponded to a possible interpretation of the sentence whenever they thought its meaning was ambiguous. The number of responses given by each participant was counted and then the proportion was calculated of chosen interpretation(s) in each 
experimental condition (i.e. forward anaphora with overt subject and with null subject, backward anaphora with overt and with null subject). For all types of items, an ANOVA was performed on the percentages obtained for the two groups.

\section{Results}

The percentages of responses given by the two groups are provided by Table 1. Let us begin with the forward anaphora condition. The distribution of responses in the PVT is shown in Figures 1 and 2.

In the forward anaphora with overt pronoun condition, as shown in Figure 1, a significant effect was found for Referent type $[F(2,64)=$ 85.618; $p<.001]$. There is also a significant interaction between the two variables Referent type and Experimental group $[F(2,64)=$ 8.739; $p<.001]$.

More precisely, when the subject of the subordinate clause is an overt pronoun, the monolingual control group clearly preferred the interpretation in which the antecedent is to the complement in the main clause (81.8\% of preferences). This choice is also favoured by the L2 learners (59.7\%), but to a significantly lesser extent; the difference between the two groups is significant $[F(1,32)=11.49 ; p=.002]$. On the other hand, the NNS group chose the interpretation in which the pronominal subject of the subordinate clause is coreferent with the NP subject of the main clause significantly more often than the monolingual control group $(26 \%$ vs. $7.6 \%),[F(1,32)=10.79 ; p=.002]$.

As for the forward anaphora sentences with null subjects, no significant difference was found between the L2 learners and the control group in the choice of referent for the null subject, as shown in Figure 2.

Overall there is a main effect for Referent type $[F(2.64)=30.822$; $p<.001]$, but no significant effect for Group, or interaction for Referent*Group.

For participants in both groups the null subject can be ambiguously interpreted as coreferent with either the complement of the matrix clause (44\% of the responses for the control group and $43.13 \%$ for the L2 learners) or the subject (50.7\% for the control group, $45.6 \%$ for the L2ers).

Let us now turn to the backward anaphora condition, the results of which are displayed in Figures 3 and 4. 


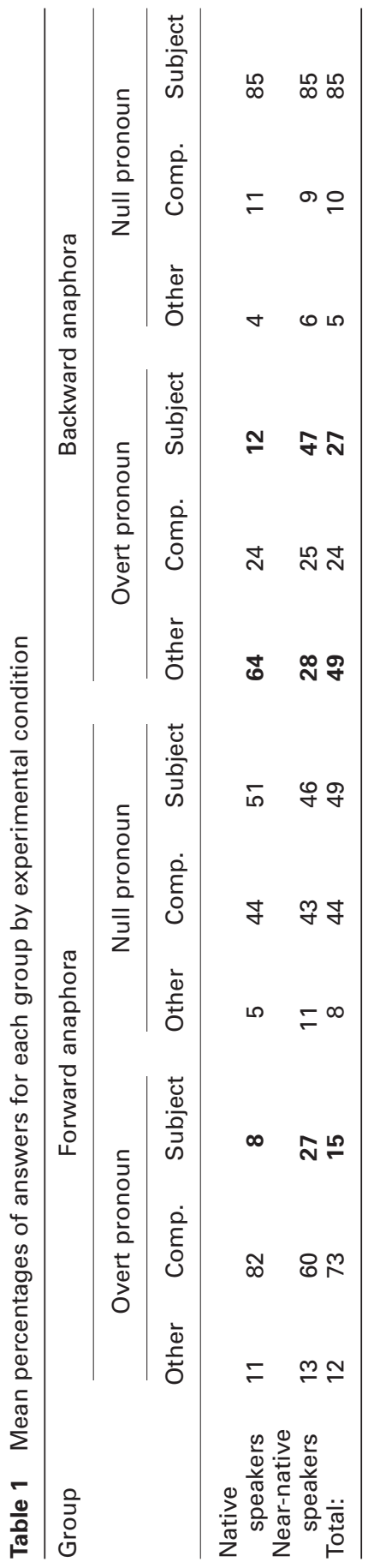


Picture verification task

Forward anaphora with overt subjects

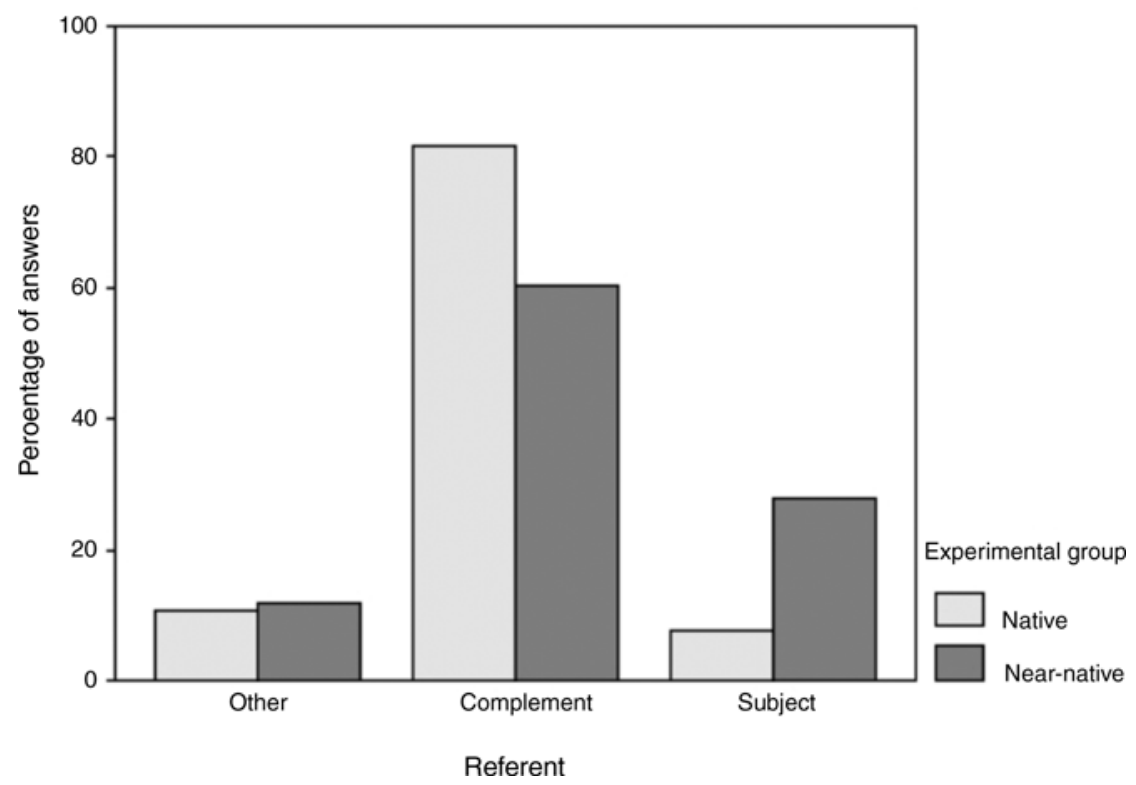

Figure 1 Antecedent assignment in forward anaphora sentences with overt pronouns

In the backward anaphora with overt pronoun condition, shown in Figure 3, we have a significant effect for Referent $[F(2,64)=4.407$; $p=.016]$. The data also show a highly significant interaction between Referent and Group $[F(2,64)=10.456 ; p<.001]$.

That is to say, when the subject of the subordinate clause is an overt pronoun, the NSs in the Italian control group prefer to interpret it as referring to the extralinguistic antecedent not mentioned in the matrix clause $(63.6 \%$ of preferences). This antecedent is chosen by the NNSs only $28.4 \%$ of the times; the difference between the two groups is significant $[F(1,32)=12.154 ; p=.001$. The most-chosen antecedent for the overt pronoun among the NNSs is the NP subject of the matrix clause, with $46.9 \%$ of preferences. This choice is clearly disfavoured by the NSs (12.5\% of preferences); the difference between the two groups is significant $[F(1,32)=16.330 ; p<.001]$. 
Picture verification task

Forward anaphora with null subject

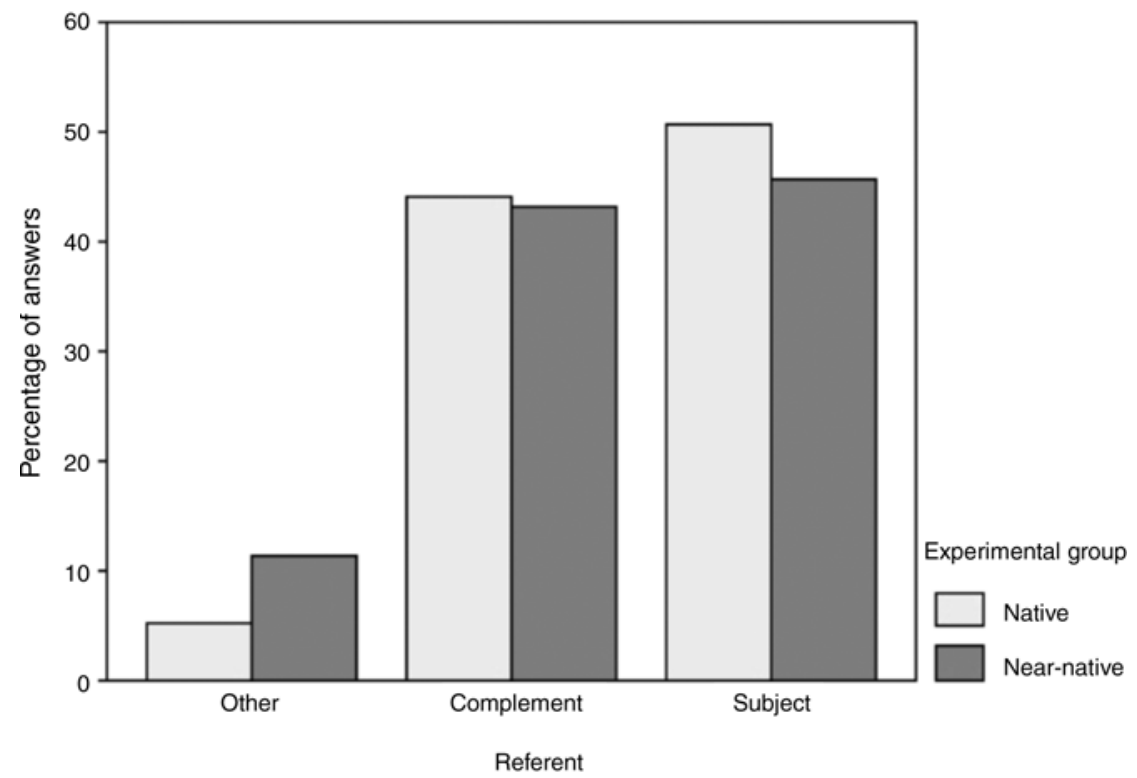

Figure 2 Antecedent assignment in forward anaphora sentences with null pronouns

In contrast, when the subject of the subordinate clause is null there is no significant difference between the control group and the L2 learners in their choices of antecedents. This pattern is shown in Figure 4. As can clearly be seen from Figure 4, in this condition there is a very significant main effect for Referent type $[F(2,64)=254.245$; $p<.001]$, but no significant effect for group and no significant interactions. Both groups prefer to interpret the null subject as coreferent with the NP subject of the matrix clause $(84.4 \%$ for the control group and $84.3 \%$ for the L2ers). The other two possibilities are rarely considered by either group.

\section{Discussion}

This experiment was designed to test whether the interpretation of subject pronouns in intrasentential contexts by near-native adult speakers of Italian is different from that of native Italian speakers. One of the 
Picture verification task

Backward anaphora with overt pronoun

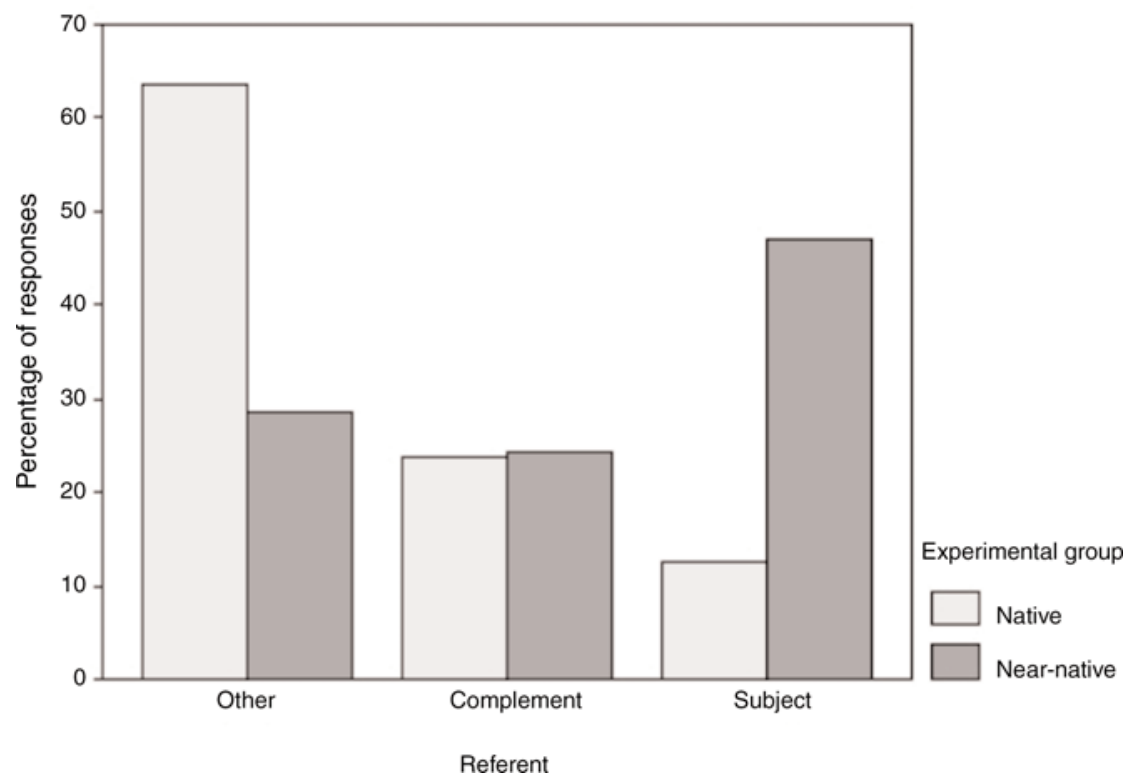

Figure 3 Antecedent assignment in backward anaphora sentences with overt pronouns

predictions was that more differences would be found with respect to overt pronouns than with null pronouns. The other prediction was that the two groups would be more divergent in their interpretation of backward anaphora than in forward anaphora. The overall results support both predictions, but they also reveal some unanticipated aspects of both native and non-native interpretation.

Carminati's theory would predict, for native speakers, that the matrix subject would be the favoured antecedent for null pronouns because of the strong bias of the PAS. While it is generally the case that NSs opt for subject assignment when they encounter a null pronoun, this is the clearly-preferred assignment only for backward anaphora sentences. In forward anaphora sentences, preferences are equally divided between the subject and the complement of the matrix clause. It seems that the pragmatic plausibility, topicality and accessibility (in terms of recency of presentation) of the complement all converge in overriding the PAS 
Picture verification task

Backward anaphora with null pronoun

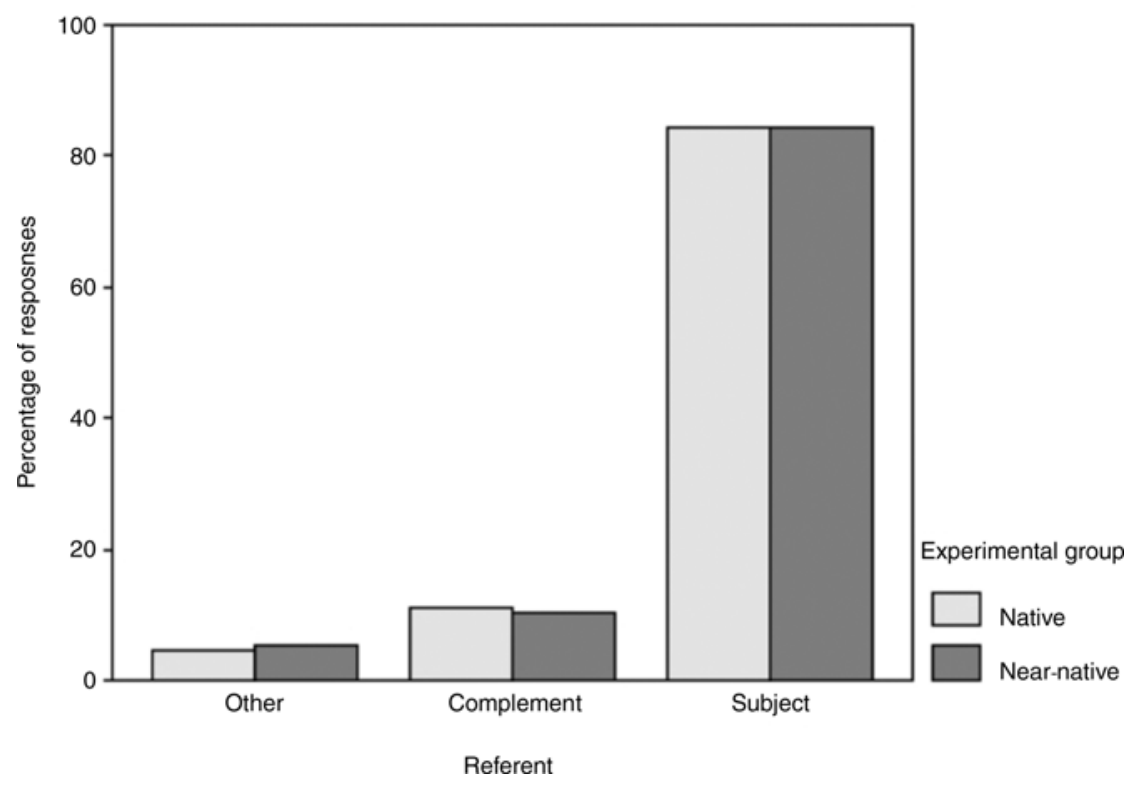

Figure 4 Antecedent assignment in backward anaphora sentences with null pronouns

and its bias against non-subject referents. In backward anaphora sentences, on the other hand, a convergence of factors strongly biases native responses toward the matrix subject in antecedent assignment. Both the PAS and the 'active parser' tendency to resolve the dependency as soon as possible in the matrix subject position lead to this solution. The native speakers in fact overwhelmingly choose the subject antecedent in this case, and regard the complement and the extralinguistic referent as unlikely possibilities. The near-native speakers display similar patterns of preferences to the natives in both forward and backward anaphora sentences. This strong similarity suggests that they have acquired target-like processing strategies for anaphora resolution of null pronouns, and are sensitive to the same structural constraints as native speakers in processing backward anaphora.

The results for anaphora resolution with overt pronouns tell a different story. Based on the PAS, the prediction would be that overt pronouns are biased towards non-subject antecedents, but this preference is 
not as strong as that of null pronouns toward subject antecedents. However, the bias should be stronger in ambiguous contexts in which its relaxation may lead to misinterpretation. Since the sentences used in this experiment are ambiguous, the expectation would be that native speakers would tend to respect the PAS.

The native speakers' responses are in line with this expectation. In forward anaphora sentences, the preferred antecedent for the overt pronoun is the complement, followed at a great distance by the subject and the extralinguistic referent, which are considered as very marginal candidates. In backward anaphora sentences, the native speakers display a strong preference for the extralinguistic referent, followed by the complement as a distant second possibility; the subject is chosen very infrequently in this condition. It appears that the conflict between the PAS and the 'active filler' strategy is resolved by native speakers by giving priority to the PAS at the expense of the other constraint. In this case, the extralinguistic referent is the preferred choice, despite its pragmatic markedness and the fact that it requires going outside the linguistic context, thus contravening a well-known preference for finding pronoun antecedents within the clause. It remains to be explained why the complement is not, on the whole, considered a likely antecedent in this context.

The near-natives behave differently from the natives, and also show different patterns of preference in forward and backward anaphora. In forward anaphora, the near-natives have the same preference as the native speakers for the complement as the most likely antecedent for the overt pronoun. However, they select the matrix subject significantly more often than the natives. In backward anaphora, the subject is selected as the best antecedent in the great majority of cases, while the extralinguistic referent, which is the favourite option in the native responses, is chosen far less frequently. The near-natives therefore violate the PAS, to different extents, in both forward and backward anaphora. Unlike the native speakers, they give priority in backward anaphora to the Active Gap-Filler strategy, which they have in their native language. In addition, they may have insufficient resources, unlike the native speakers, to entertain the possibility of the extralinguistic referent being the antecedent for the overt pronoun.

It is worth comparing the results of this study with those of Serratrice (2005), which is the only other study of bilingualism that explicitly refers 
to Carminati's proposal. Serratrice conducted a study of the interpretation of forward and backward anaphora by older (age 8) bilingual English-Italian children and age-matched monolingual Italian children. The adult monolingual Italian controls were those of Tsimpli et al. (2004). She used a reduced version of the PVT task employed in our study. Her results indicate that the three groups do not differ with respect to the interpretation of null subjects: all groups indicate the matrix subject as the preferred antecedent, although the bilingual children also allow the object to be a possible antecedent, particularly in the forward anaphora condition. However, the three groups differ in their antecedent choices for the overt pronoun, with the bilingual children selecting the subject as an antecedent more often than the other two groups. Serratrice's study also highlights potentially important differences between adult and child monolinguals: monolingual children behave qualitatively like adults, showing similar relative preferences, but they inappropriately select the matrix subject as an antecedent for the overt pronoun more often than the monolingual adults, although not as often as the bilingual children. Both child groups' responses in backward anaphora with overt pronouns are divided between subject and complement: the extralinguistic referent is a very infrequent choice. It is possible that, as Serratrice suggests, the construction of an extralinguistic context in which this referent can be a plausible antecedent exceeds the children's processing capacities. It is also not implausible that the degree of contextual sensitivity in the PAS for overt pronouns develops with age. What is noteworthy is that monolingual children solve integration difficulties by relaxing the PAS for the overt pronoun, rather than for the null pronoun, consistently with the weaker antecedent bias of the overt pronoun in general.

\section{Conclusions}

What can be concluded from this study? There are three scenarios that may account for the results:

1) The NNSs do not have the syntax of pronominal subjects (i.e. a null-subject grammar).

2) The NNSs do have a null-subject grammar, but do not have optimal strategies to process pronominal subjects (i.e. the PAS). 
3) The NNSs do have both a null-subject grammar and the PAS, but they may not have the necessary processing resources to integrate multiple sources of information consistently.

Scenario 1 can be ruled out on the basis of the fact that near-native speakers of Italian can and do use both null and overt subjects appropriately. ${ }^{10}$ Scenario 2 is disconfirmed to the extent that these speakers consistently respect the PAS in interpreting null pronouns. However, they are more tolerant than native speakers toward violations of the PAS for overt pronouns. It has been demonstrated that native speakers also display some flexibility in their antecedent assignment preferences for overt pronouns; this flexibility, however, is inversely correlated with the degree of ambiguity that inappropriate uses of overt pronouns may generate. In other words, native speakers seem to be guided by a tendency to avoid misinterpretation. Near-natives, in contrast, are less sensitive to this factor and are therefore more prone to overgeneralize overt pronouns inappropriately. Scenario 3 is supported by the radically different antecedent assignment strategies adopted by natives and near-natives in backward anaphora sentences. The greater processing demands posed by this type of sentences lead near-native speakers to rely exclusively on the active gap-filler strategy (possibly imported from their L1), incurring in a violation of the PAS and disregarding the available solution of searching for antecedents outside the sentence. ${ }^{11}$

This account of near-natives' anaphora resolution reinterprets in processing terms the solution previously proposed in representational terms (Sorace, 2000; 2003; Tsimpli et al., 2004). According to a representational account, near-native speakers would have a wider range of interface mappings for pronominal subjects than native speakers: while the latter have one-to-one mappings between null pronouns and the feature [-Topic Shift], and between the overt pronoun and the feature

\footnotetext{
${ }^{10}$ Near-native speakers also demonstrated knowledge of other syntactic properties of null subject grammars, such as postverbal subjects, in other tasks that were administered together with the PVT; see also Belletti et al., 2005.

${ }^{11}$ The off-line task employed in this study does not allow the exploration of other possible processing deficits in near-native speakers. One of this is the analogue to the 'Slow Syntax' hypothesis proposed for Broca's aphasics by Piñango and Burkhardt (2001): near-natives may conceivably have slower access to syntactic mechanisms, so that the PAS would apply in a less automatic and efficient fashion than in native speakers.
} 
[+Topic Shift], near-natives could also map the overt pronoun to the [-Topic Shift] feature, essentially treating the overt Italian pronoun as if it were an English weak unstressed pronoun. Within the processing theory adopted in this article, the near-natives have a native-like strict PAS for null pronouns, but a less-strict PAS for overt pronouns, which allows coreference both with a subject and a non-subject antecedent, regardless of contextual ambiguity. The representational and the processing accounts are very similar. Is there a role for transfer from English in the processing account?

According to Carminati, the processing strategies deployed in the interpretation of subject pronouns are similar in Italian and English, but they obviously apply to different inventories of pronominal forms: null and (unstressed) overt pronouns in Italian, unstressed and stressed pronouns in English. ${ }^{12}$ She points out that it is incorrect to assume (as in Luján, 1986) a correspondence between null Italian pronouns and unstressed English pronouns, on the one hand, and overt Italian pronouns and stressed English pronouns, on the other. Assuming that the PAS is at work in both languages, the prediction is that unstressed English pronouns may correspond to both null and (unstressed) overt Italian pronouns: a pronoun that corefers with a subject antecedent is null in Italian and unstressed in English, whereas a pronoun that corefers with a non-subject antecedent is an unstressed overt pronoun in both languages.

The less restrictive PAS for overt subjects in the Italian near-native grammar of native English speakers may therefore also be at least in part related to the fact that there is no one-to-one correspondence between English and Italian pronoun inventories. Notice, however, that both the representational and the processing accounts need to consider the variability found in monolingual Italians with respect to overt pronouns. We have seen how the PAS may be relaxed in unambiguous contexts, often leading the processor to allow the coreference between overt pronouns and subject antecedents. This is in line with Cardinaletti's (2005) observation that there is an ongoing change in the

\footnotetext{
${ }^{12}$ Overt pronouns may also be stressed in Italian for contrastive or emphatic reasons. A stressed Italian pronoun behaves like a stressed English pronoun: the PAS does not apply to stressed pronouns, and therefore a stressed pronoun (which can only be overt) can refer back to a subject antecedent.
} 
overt pronoun in Italian leading to its reanalysis from strong to weak. Therefore there is a real sense in which the overt pronoun is acquiring the status of an unmarked, default form in Italian. In the case of native English speakers tested in this study, their L1 may be an additional factor conspiring with the pre-existing tendency of the overt pronoun to act as a default.

To conclude, this article has provided experimental data and arguments in support of the view that the residual optionality found in the pronominal subjects of L1 English near-native speakers of L2 Italian may be the result of indeterminacy at the syntax-discourse interface and, specifically, in the processing strategies linking pronouns to their antecedents. This indeterminacy magnifies existing instabilities in Italian, and may not be exclusive to non-native speakers of Italian coming from a non-null subject language; indeed, it appears to characterize different domains of language contact and bilingualism. Future research will tell exactly how representational properties and characteristics of the language processor interact in the near-native grammar while L2 speakers engage in on-line production and interpretation of pronominal subjects.

\section{References}

Alonso-Ovalle, L., Clifton, C., Frazier, L. and Férnandez-Solera, S. 2002: Null vs. overt pronouns and the topic-focus articulation in Spanish. Journal of Italian Linguistics 14, 151-69.

Belletti, A., Bennati, E. and Sorace, A. 2005: Theoretical and developmental issues in the syntax of subjects: evidence from near-native Italian. Unpublished manuscript, University of Siena and University of Edinburgh.

Bini, M. 1993: La adquisicíon del italiano: mas allá de las propiedades sintácticas del parámetro pro-drop [The acquisition of Italian: beyond the syntactic properties of the pro-drop parameter]. In Liceras, L., editor, La linguistica y el analisis de los sistemas no natives. Doverhouse, 126-39.

Burkhardt, P. 2005: The syntax-discourse interface. Representing and interpreting dependency. John Benjamins.

Cardinaletti, A. 2005: La traduzione: un caso di attrito linguistico [Translation: a case of linguistic attrition]. In Cardinaletti, A. and Garzone, G., editors, L'italiano delle traduzioni. Franco Angeli, 59-84.

Carminati, M.N. 2002: The processing of Italian subject pronouns. PhD Thesis, University of Massachusetts Amherst. 
- 2005: Processing reflexes of the feature hierarchy (Person $>$ Number $>$ Gender) and implications for linguistic theory. Lingua 115, 259-85.

Clahsen, H. and Felser, C. 2006: Grammatical processing in first and second language learners. Applied Psycholinguistics 27, 3-42.

Cowart, W. and Cairns, H.S. 1987: Evidence for an anaphoric mechanism within syntactic processing. Some reference relations defy semantic and pragmatic constraints. Memory and Cognition 15, 318-31.

Filiaci, F. 2003: The acquisition of the properties of Italian null and overt subjects by English native speakers. MSc Dissertation, University of Edinburgh.

Grimshaw, J. and Samek-Lodovici, V. 1998: Optimal subjects and subject universals. In Barbosa, P., Fox, D., Hangstrom, P., McGinnis, M. and Pesetsky, D., editors, Is the best good enough? Optimality and competition in syntax. MIT Press, 193-219.

Guasti, T. 2002: Language acquisition: the growth of grammar. MIT Press.

Hacohen, A. and Schaeffer, J. 2005: Subject realization in early Hebrew/English bilingual acquisition: the role of crosslinguistic influence. Unpublished manuscript, Ben-Gurion University of the Negev.

Hawkins, R. 2001: Second language syntax. Blackwell.

Hawkins, R. and Chan, C. 1997: The partial availability of Universal Grammar in second language acquisition: the 'failed functional features hypothesis. Second Language Research 13, 187-226.

Helland, C. 2004: The interpretable-uninterpretable feature distinction and attrition in Catalan. Unpublished paper presented at the GLOW conference, Thessaloniki.

Holmberg, A. 2005: Is there a little pro? Evidence from Finnish. Linguistic Inquiry 33, 533-64.

Kazanina, N. 2005: The acquisition and processing of backward anaphora. Unpublished PhD dissertation, University of Maryland, College Park.

Kazanina, N.E., Lieberman, M. Phillips, C. and Yoshida, M. 2005: Constraints on coreference in the online processing of backwards anaphora. Poster presented at the 18th Annual CUNY Sentence Processing Conference, University of Arizona, Tucson.

Lapidus, N. and Otheguy, R. 2005: Contact induced change? Overt nonspecific ellos in Spanish in New York. In Sayahi, L. and Westmoreland, M., editors, Selected proceedings of the Second Workshop on Hispanic Sociolinguistics. Cascadilla Press.

Luján, M. 1986: Stress and binding of pronouns. In Farley, A.M., Farley, P.T. and McCullough, K.E., editors, Chicago Linguistics Society 22, 248-62.

Montalbetti, M. 1984: After Binding. PhD dissertation, MIT.

Montrul, S. 2004: Subject and object expression in Spanish Heritage speakers: a case of morphosyntactic convergence. Bilingualism: Language and Cognition 7, 125-42. 
Müller, N. and Hulk, A. 2001: Crosslinguistic influence in bilingual language acquisition: Italian and French as recipient languages. Bilingualism: Language and Cognition 4, 1-22.

Müller, N., Cantone, K., Kupisch, T. and Schmitz, K. 2002: Zum Spracheneinfluss in bilingualen Erstspracherwerb: Italienisch-Deutsch [Crosslinguistic influence in bilingual first language acquisition: ItalianGerman]. Linguistische Berichte 190, 157-206.

Müller, N., Kupisch, T., Schmitz, K. and Cantone, K. 2006: Einfürhung in die Mehrsprachigkeitsforschung [Introduction to research on multilingualism]. Narr Verlag.

Ordóñez, F. and Treviño, E. 1999: Left dislocated subjects and the pro-drop parameter: a case study of Spanish. Lingua 107, 39-68.

Paradis, J. and Navarro, S. 2003: Subject realization and cross-linguistic interference in the bilingual acquisition of Spanish and English: what is the role of input? Journal of Child Language 30, 1-23.

Piñango, M.M. and Burkhardt, P. 2001: Pronominals in Broca's aphasia comprehension: the consequences of syntactic delay. Brain and Language 79, 167-68.

Pinto, M. 2004: Subject pronouns in bilinguals: interference or maturation? Unpublished manuscript, University of Utrecht.

Roeper, T. 1999: Universal bilingualism. Bilingualism: Language and Cognition 2, 169-86.

Serratrice, L., Sorace, A. and Paoli, S. 2004: Transfer at the syntaxpragmatics interface: subjects and objects in Italian-English bilingual and monolingual acquisition. Bilingualism: Language and Cognition 7, 183-206.

Sorace, A. 2000: Syntactic optionality in non-native grammars. Second Language Research 16, 93-102.

— 2003: Ultimate L2 attainment. In Long, M. and Doughty, C., editors, Handbook of second language acquisition. Blackwell, 130-51.

2004: Native language attrition and developmental instability at the syntax-discourse interface: data, interpretations and methods. Bilingualism: Language and Cognition 7, 143-45.

2005: Selective optionality in language development. In Cornips, L. and Corrigan, K.P., editors, Syntax and variation. Reconciling the Biological and the Social. John Benjamins, 55-80.

2006: Possible manifestations of shallow processing in advanced second language speakers. Applied Psycholinguistics 27, 88-91.

Toribio, A.J. 2004: Convergence as an optimization strategy in bilingual speech: evidence from code-switching. Bilingualism: Language and Cognition 7, 165-73.

Tsimpli, I.M. 1997: Resumptive features and L2A: a minimalist account. Boston University Conference on Language Development 21, 639-55. 
Tsimpli, I.M., Sorace, A., Heycock, C. and Filiaci, F. 2004: First language attrition and syntactic subjects: a study of Greek and Italian near-native speakers of English. International Journal of Bilingualism 8, 257-77.

van Gompel, R.P. and Liversedge, S.P. 2003: The influence of morphological information on cataphoric pronoun assignment. Journal of Experimental Psychology: Learning, Memory and Cognition 29, $128-39$.

White, L. and Genesee, F. 1996: How native is near-native? The issue of ultimate attainment in adult second language acquisition. Second Language Research 12, 233-65.

Appendix 1 Picture verification task: example of forward anaphora with null pronoun

La mamma dà un bacio alla figlia, mentre si mette il cappotto.

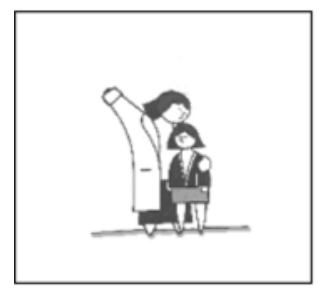

1

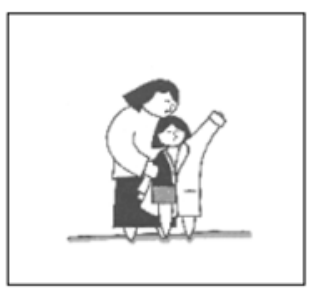

2

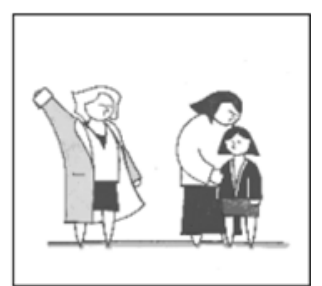

3

Appendix 2 Summary of individual data

Table 2 Forward anaphora, individual data for the native group (percentages)

\begin{tabular}{lccccccc}
\hline \multirow{2}{*}{ Subject ID } & \multicolumn{3}{c}{ Overt subject } & & \multicolumn{3}{c}{ Null Subject } \\
\cline { 2 - 3 } & Other & Comp. & Subject & & Other & Comp. & Subject \\
\hline AF_206011 & 17 & 17 & 67 & & 0 & 38 & 63 \\
AFZ_231031 & 0 & 20 & 80 & & 0 & 20 & 80 \\
AT_230121 & 0 & 20 & 80 & & 0 & 40 & 60 \\
CF_230081 & 0 & 0 & 100 & & 0 & 80 & 20 \\
CP_208111 & 0 & 33 & 67 & & 0 & 20 & 80 \\
ES_224031 & 0 & 17 & 83 & & 0 & 50 & 50 \\
ET_231081 & 0 & 20 & 80 & & 0 & 67 & 33 \\
EZ_202041 & 0 & 0 & 100 & & 0 & 50 & 50 \\
FP_230083 & 0 & 20 & 80 & & 0 & 60 & 40 \\
GB_231033 & 0 & 0 & 100 & & 0 & 0 & 100 \\
GF_228091 & 0 & 0 & 100 & & 17 & 33 & 50 \\
GR_230082 & 17 & 0 & 83 & & 20 & 20 & 60 \\
LP_216101 & 20 & 0 & 80 & & 0 & 44 & 56 \\
LR_209101 & 0 & 20 & 80 & & 0 & 67 & 33 \\
LV_202012 & 0 & 40 & 60 & & 0 & 43 & 57 \\
\hline
\end{tabular}


Table 2 Continued

\begin{tabular}{lccccccc}
\hline Subject ID & \multicolumn{3}{c}{ Overt subject } & & \multicolumn{3}{c}{ Null Subject } \\
\cline { 2 - 4 } & Other & Comp. & Subject & & Other & Comp. & Subject \\
\hline MO_203041 & 0 & 0 & 100 & & 0 & 43 & 57 \\
MP_210101 & 17 & 0 & 83 & & 0 & 57 & 43 \\
PC_231032 & 0 & 17 & 83 & & 0 & 50 & 50 \\
RS_205091 & 0 & 0 & 100 & & 40 & 60 & 0 \\
SR_206122 & 17 & 0 & 83 & & 17 & 50 & 33 \\
\hline
\end{tabular}

Table 3 Forward anaphora, individual data for the near-native group (percentages)

\begin{tabular}{|c|c|c|c|c|c|c|}
\hline \multirow[t]{2}{*}{ Subject ID } & \multicolumn{3}{|c|}{ Overt subject } & \multicolumn{3}{|c|}{ Null subject } \\
\hline & Other & Comp. & Subject & Other & Comp. & Subject \\
\hline AS-31205051 & 0 & 71 & 28 & 11 & 33 & 56 \\
\hline AS-32705052 & 0 & 55 & 44 & 9 & 45 & 45 \\
\hline DJ-31305052 & 14 & 71 & 14 & 0 & 33 & 67 \\
\hline DO-30605051 & 45 & 45 & 9 & 33 & 33 & 33 \\
\hline HC-31005051 & 0 & 8 & 16 & 9 & 45 & 45 \\
\hline KMH-3270501 & 0 & 62 & 37 & 0 & 50 & 50 \\
\hline LA-31105051 & 20 & 80 & 0 & 0 & 0 & 100 \\
\hline MS-30405051 & 14 & 42 & 42 & 17 & 50 & 33 \\
\hline SB-32104051 & 28 & 57 & 14 & 17 & 50 & 33 \\
\hline SL-32004051 & 28 & 57 & 14 & 25 & 50 & 25 \\
\hline JDP-321071 & 20 & 80 & 0 & 0 & 43 & 57 \\
\hline SC-307071 & 0 & 33 & 67 & 17 & 50 & 33 \\
\hline BX-310071 & 0 & 80 & 20 & 20 & 20 & 60 \\
\hline SA-326062 & 0 & 50 & 50 & 0 & 56 & 44 \\
\hline
\end{tabular}

Table 4 Backward anaphora, individual data for the native group (percentages)

\begin{tabular}{lrrrrrrrr}
\hline Subject ID & \multicolumn{3}{c}{ Overt subject } & & \multicolumn{3}{c}{ Null subject } \\
\cline { 2 - 3 } \cline { 7 - 8 } & Other & Comp. & Subject & & Other & Comp. & Subject \\
\hline AF_206011 & 60 & 40 & 0 & & 17 & 17 & 67 \\
AFZ_231031 & 20 & 80 & 0 & & 0 & 20 & 80 \\
AT_230121 & 100 & 0 & 0 & & 0 & 20 & 80 \\
CF_230081 & 20 & 60 & 20 & & 0 & 0 & 100 \\
CP_208111 & 100 & 0 & 0 & & 0 & 33 & 67 \\
ES_224031 & 0 & 0 & 100 & & 0 & 17 & 83 \\
ET_231081 & 75 & 25 & 0 & & 0 & 20 & 80 \\
EZ_202041 & 60 & 20 & 20 & & 0 & 0 & 100 \\
FP_230083 & 100 & 0 & 0 & & 0 & 20 & 80 \\
GB_231033 & 80 & 0 & 20 & & 0 & 0 & 100 \\
GF_228091 & 60 & 40 & 0 & & 0 & 0 & 100 \\
GR_230082 & 100 & 0 & 0 & & 17 & 0 & 83 \\
LP_216101 & 83 & 17 & 0 & & 20 & 0 & 80 \\
LR_209101 & 17 & 33 & 50 & & 0 & 20 & 80 \\
LV_202012 & 60 & 20 & 20 & & 0 & 40 & 60 \\
\hline & & & 0 & & & & & continued
\end{tabular}


368 Anaphora resolution in near-native speakers of Italian

Table 4 Contiuned

\begin{tabular}{lccccccc}
\hline Subject ID & \multicolumn{3}{c}{ Overt subject } & & \multicolumn{3}{c}{ Null subject } \\
\cline { 2 - 3 } & Other & Comp. & Subject & & Other & Comp. & Subject \\
\hline MO_203041 & 57 & 43 & 0 & & 0 & 0 & 100 \\
MP_210101 & 60 & 40 & 0 & & 17 & 0 & 83 \\
PC_231032 & 100 & 0 & 0 & & 0 & 17 & 83 \\
RS_205091 & 80 & 20 & 0 & & 0 & 100 \\
SR_206122 & 40 & 40 & 20 & & 17 & 0 & 83 \\
\hline
\end{tabular}

Table 5 Backward anaphora, individual data for the near-native group (percentages)

\begin{tabular}{|c|c|c|c|c|c|c|}
\hline \multirow[t]{2}{*}{ Subject ID } & \multicolumn{3}{|c|}{ Overt subject } & \multicolumn{3}{|c|}{ Null subject } \\
\hline & Other & Comp. & Subject & Other & Comp. & Subject \\
\hline AS-31205051 & 17 & 33 & 50 & 0 & 29 & 71 \\
\hline AS-32705052 & 13 & 25 & 63 & 0 & 17 & 83 \\
\hline DJ-31305052 & 38 & 0 & 63 & 0 & 0 & 100 \\
\hline DO-30605051 & 56 & 33 & 11 & 31 & 38 & 31 \\
\hline HC-31005051 & 0 & 60 & 40 & 0 & 0 & 100 \\
\hline KMH-3270501 & 20 & 0 & 80 & 0 & 0 & 100 \\
\hline LA-31105051 & 100 & 0 & 0 & 0 & 0 & 100 \\
\hline MS-30405051 & 14 & 14 & 71 & 0 & 0 & 100 \\
\hline SB-32104051 & 29 & 43 & 29 & 17 & 0 & 83 \\
\hline SL-32004051 & 22 & 33 & 44 & 22 & 22 & 56 \\
\hline JDP-321071 & 33 & 33 & 33 & 0 & 0 & 100 \\
\hline SC-307071 & 17 & 50 & 33 & 17 & 0 & 83 \\
\hline BX-310071 & 0 & 20 & 80 & 0 & 20 & 80 \\
\hline SA-326062 & 22 & 22 & 56 & 0 & 38 & 62 \\
\hline
\end{tabular}

